\title{
LOW-DOSE PROTAMINE BASED ON HEPARIN-PROTAMINE TITRATION METHOD REDUCES PLATELET DYSFUNCTION AFTER CARDIOPULMONARY BYPASS
}

Osamu Shigeta, MDa

Hiroshi Kojima, MD $^{\mathrm{b}}$

Yuji Hiramatsu, MD

Tomoaki Jikuya, MD

Yasushi Terada, $\mathrm{MD}^{\mathrm{a}}$

Naotaka Atsumi, MD

Yuzuru Sakakibara, MD

Toshiro Nagasawa, $\mathrm{MD}^{\mathrm{b}}$

Toshio Mitsui, MD
Objective: The heparin-protamine titration method that uses the Hepcon hemostasis management system (Medtronic HemoTec Inc, Englewood, Colo) reduced blood loss in cardiac surgery in previous reports, but the mechanism is not fully understood. This study tests the hypothesis that reduced protamine administration preserves platelet function in human cardiac surgery. Methods: Platelet count, $\alpha$-granule secretion, and aggregation to thrombin before and after cardiopulmonary bypass in human beings were evaluated. In the control group $(n=14)$, a fixed dose of protamine $(3 \mathrm{mg} / \mathrm{kg})$ was administered. In the titration group $(\mathrm{n}=20)$, protamine doses were based on the heparin concentration measured by the Hepcon system. Results: Heparin concentrations before protamine administration were higher in the titration group $(P=.0012)$, but protamine doses of patients in the titration group were markedly lower than those of the control group $(P<.0001)$. During protamine infusion at a rate of 0.3 $\mathrm{mg} \cdot \mathrm{kg}^{-1} \cdot \mathrm{min}^{-1}$, the percentage of granule membrane protein-140-positive platelets significantly increased in the control group compared with the titration group $(\mathbf{1 8 . 8 \%} \pm \mathbf{8 . 6} \%$ vs $\mathbf{1 3 . 0 \%} \pm \mathbf{5 . 3 \%}, P=\mathbf{0 1 8 8})$. After protamine administration, aggregation of washed platelets to thrombin recovered almost to the preoperative level in the titration group; however, it remained lower in the control group $(20 \% \pm 20 \%$ vs $55 \% \pm 18 \%, P=$ .0009). Conclusion: Low-dose administration of protamine, based on a heparin-protamine titration method, restores not only the blood coagulation but also the platelet responses to thrombin and attenuates platelet $\alpha$ granule secretion during heparin neutralization. Overdose of protamine activates platelets and may predispose patients to excessive bleeding after cardiac surgery. (J Thorac Cardiovasc Surg 1999;118:354-60)
$P^{n}$ otamine, a mixture of simple proteins (molecular weight, 4,000-10,000) is isolated from fish sperm, which contains a high percentage $(>70 \%)$ of arginine. ${ }^{1}$ Highly acidic heparin combines stoichiometrically with the base protamine, resulting in a neutral inactive salt. ${ }^{2}$ Protamine sulfate has numerous and infrequently fatal side effects such as systemic arterial hypotension, peripheral vasodilation, bradycardia, decreased cardiac output, pulmonary artery hypotension or hypertension,

From the Divisions of Cardiovascular Surgery ${ }^{\mathrm{a}}$ and Hematology, ${ }^{\mathrm{b}}$ Institute of Clinical Medicine, University of Tsukuba, Tsukuba, Ibaraki, Japan.

Received for publication Nov 24, 1998; revisions requested Feb 4, 1999; revisions received March 25, 1999; accepted for publication April 27, 1999.

Address for reprints: Osamu Shigeta, MD, Institute of Clinical Medicine, University of Tsukuba, Tsukuba, Ibaraki, 305, Japan.

Copyright $\odot 1999$ by Mosby, Inc.

$0022-5223 / 99 \$ 8.00+0 \quad \mathbf{1 2 / 1 / 9 9 5 9 9}$ decreased oxygen consumption, thrombocytopenia, and leukopenia. ${ }^{3,4}$ However, protamine is still used routinely to reverse heparin anticoagulation. It is commonly believed that too much protamine is deleterious, but the mechanism is not fully understood.

In this study, we focus on platelet function to evaluate the effect of low-dose protamine relative to the heparin dose after cardiopulmonary bypass (CPB).

\section{Material and methods}

Heparin used in this study was from gut mucosa (Novo Nordisk A/S, Bagsvaerd, Denmark), and we considered that 1 unit of heparin was equivalent to $10 \mu \mathrm{g}$ of protamine (Novo Nordisk).

Phase I (ex vivo, patient analysis). From August 1997 to August 1998, platelet function during CPB was evaluated in 42 patients who were selected randomly at the University of Tsukuba Hospital. Informed consent was obtained from all patients enrolled in this protocol. They did not receive any antiplatelet drugs within 7 days before the operation and 
underwent CPB without aprotinin. All patients were anesthetized with an opioid-based technique (fentanyl citrate). Extracorporeal circulation was accomplished with a roller pump and a membrane oxygenator (HPO-25RHF, Mera, Japan). Systemic hypothermia was maintained at $30^{\circ} \mathrm{C}$ to $32^{\circ} \mathrm{C}$ during aortic crossclamping. The $\mathrm{CPB}$ circuit was routinely primed with $1.5 \mathrm{~L}$ of Veen-D solution (glucose-acetate Ringer's solution), sodium bicarbonate $\left(\mathrm{NaHCO}_{3}\right) 33 \mathrm{mEq} / \mathrm{L}$, mannitol $27 \mathrm{mg} / \mathrm{L}$, and heparin 3.3 units $/ \mathrm{mL}$.

Among 42 patients, 8 patients (6 patients in the control group and 2 patients in the titration group) were excluded because of blood transfusion including platelets before the last samples were obtained. For patients in the control group $(n=14)$, the anticoagulation and reversal protocol consisted of an initial fixed heparin dose of $300 \mathrm{U} / \mathrm{kg}, 5000$ units of heparin added to the priming fluid of the CPB circuit, and additional heparin administered when the celite activated clotting time (ACT) was less than 480 seconds. The protamine dose for the control group was fixed at $3 \mathrm{mg} / \mathrm{kg}$ and administered at a rate of $0.3 \mathrm{mg} \cdot \mathrm{kg}^{-1} \cdot \mathrm{min}^{-1}$. For the titration group $(n=20)$, we administered the same dose of initial and priming heparin that we used in the control group because the heparin dose-response test by the Hepcon hemostasis management system (Medtronic HemoTec Inc, Englewood, Colo) sometimes underestimates the initial heparin doses. Additional heparin was administered when the heparin concentration measured by the Hepcon system was less than 2.7 units $/ \mathrm{mL}$ or the celite ACT was less than 480 seconds. The neutralizing dose of protamine was based on the whole blood heparin concentration measurement using the Hepcon system, which performs heparin-protamine titration automatically within 5 minutes in the operating room. On the basis of the heparin concentration of the sample after discontinuation of CPB, $1.0 \mathrm{mg}$ of protamine per 100 units of residual heparin for total volume was administered at the same rate as in the control group. All patients underwent the operation uneventfully.

Sample preparation. Five milliliters of blood was collected from patients at 4 separate points: before the operation, after discontinuation of CPB but before protamine administration, at the end of protamine administration, and $15 \mathrm{~min}$ utes after protamine administration. All specimens from each patient were stored at room temperature until the last specimen was obtained, and then they were analyzed together. So that the platelet function test could be completed within 4 to 5 hours after the first specimen was collected, specimens in subsequent postoperative intervals (2-6 hours postoperatively) were not obtained. The blood was transferred into a syringe containing $0.75 \mathrm{~mL}$ of acid-citrate-dextrose (ACD) solution (citric acid, $6.8 \mathrm{mmol} / \mathrm{L}$; trisodium citrate, 11.2 $\mathrm{mmol} / \mathrm{L}$; glucose, $24 \mathrm{mmol} / \mathrm{L}$ ) and mixed gently. All the specimens were centrifuged at $180 \mathrm{~g}$ for 10 minutes just after the final sample was obtained. A $200 \mu \mathrm{L}$ solution of platelet-rich plasma (PRP) was fixed with $200 \mu \mathrm{L}$ of $2 \%$ paraformaldehyde (E. Merck, Darmstadt, Germany) for flow cytometric analysis. The rest of the PRP was washed for platelet aggregation study.
Table I. Demographic and operative data

\begin{tabular}{lccc}
\hline & $\begin{array}{c}\text { Control } \\
(n=14)\end{array}$ & $\begin{array}{c}\text { Titration } \\
(n=20)\end{array}$ & P value \\
\hline Age (y) & $51.7 \pm 22.6$ & $55.2 \pm 20.5$ & NS \\
Male sex (n) & 10 & 14 & \\
Weight (kg) & $46.6 \pm 18.6$ & $56.6 \pm 13.3$ & $\mathrm{NS}$ \\
CPB time (h) & $2.4 \pm 0.6$ & $2.7 \pm 0.7$ & $\mathrm{NS}$ \\
Heparin dose: final & $458 \pm 100$ & $537 \pm 973$ & .0132 \\
$\quad(\mathrm{U} / \mathrm{kg})$ & & & \\
$\begin{array}{l}\text { Heparin concentration* } \\
\quad(\mathrm{U} / \mathrm{mL})\end{array}$ & $1.39 \pm 0.32$ & $2.13 \pm 0.63$ & .0012 \\
$\begin{array}{l}\text { Protamine dose (mg/kg) } \\
\text { Protamine/heparin ratio }\end{array}$ & $0.67 \pm 0.15$ & $0.33 \pm 0.09$ & $<.0001$ \\
$\begin{array}{l}\text { Postoperative bleeding } \dagger \\
(\mathrm{mL} / \mathrm{kg})\end{array}$ & $12.3 \pm 8.6$ & $8.7 \pm 6.5$ & $\mathrm{NS}$ \\
& & & \\
\hline
\end{tabular}

Values are mean $\pm \mathrm{SD}$. $C P B$, Cardiopulmonary bypass; $N S$, not significant. *Heparin concentration evaluated by Hepcon system before protamine administration.

Washed platelets. PIPES buffer (piperazine- $N-N^{\prime}-b i s[2-$ ethanesulfonic acid]) was prepared to wash the platelets or dilute the antibodies (PIPES buffer, $5 \mathrm{mmol} / \mathrm{L}$ [Dojindo, Tokyo, Japan]; $\mathrm{NaCl}, 145 \mathrm{mmol} / \mathrm{L} ; \mathrm{KCl}, 4 \mathrm{mmol} / \mathrm{L} ; \mathrm{Na}_{2} \mathrm{HPO}_{4}$, $0.5 \mathrm{mmol} / \mathrm{L} ; \mathrm{MgCl}_{2}, 1 \mathrm{mmol} / \mathrm{L}$; glucose, $5.5 \mathrm{nmol} / \mathrm{L}$; bovine albumin, $3.5 \mathrm{mg} / \mathrm{mL}$; $\mathrm{pH}$ 7.4). The PRP was mixed with an equal volume of washing buffer $(1: 8=\mathrm{ACD}$ solution/PIPES buffer) and then centrifuged at $400 g$ for 15 minutes at room temperature. The platelet pellet was resuspended gently in PIPES buffer at a concentration of $2.0 \times 10^{8} / \mathrm{mL}$ for the assay of thrombin-induced platelet aggregation.

Phase II (in vitro, volunteer analysis). For in vitro studies, $10 \mathrm{~mL}$ of venous blood from healthy volunteers, who had no medication for at least 10 days before donation, was collected into plastic tubes containing $1.5 \mathrm{~mL}$ ACD buffer. The blood was centrifuged at $180 \mathrm{~g}$ for 10 minutes at room temperature and PRP was collected. The PRP was washed 2 times in the same way as in the in vivo study.

Detection of platelet surface cluster of differentiation (CD62) by flow cytometric analysis. Platelet surface antigen was stained by the phycoerythrin-labeled monoclonal antibody and analyzed by flow cytometry (FACSort; Becton Dickinson, Mountain View, Calif). The monoclonal antibody used in this study was CD62-PE (Becton Dickinson), a monoclonal antibody that recognizes $\alpha$-granule membrane protein (GMP-140) expressed on the platelet surface after platelet secretion. A $20-\mu \mathrm{L}$ aliquot of each fixed platelet sample was incubated with $5 \mu \mathrm{L}$ of 1:5 diluted monoclonal antibody (saturating concentration of the antibody) in the dark for 30 minutes at room temperature to allow antibody binding, and then $400 \mu \mathrm{L}$ of ISOTON II solution (Coulter, Inc, Tokyo, Japan) was added to dilute the samples.

The samples were first analyzed by forward scatter $(>350)$ and side scatter $(>450)$. A gate was set so as to include the majority of the platelets and exclude larger particles, which may be platelet aggregates or other contaminating blood cells. A fluorescence histogram was obtained for 10,000 

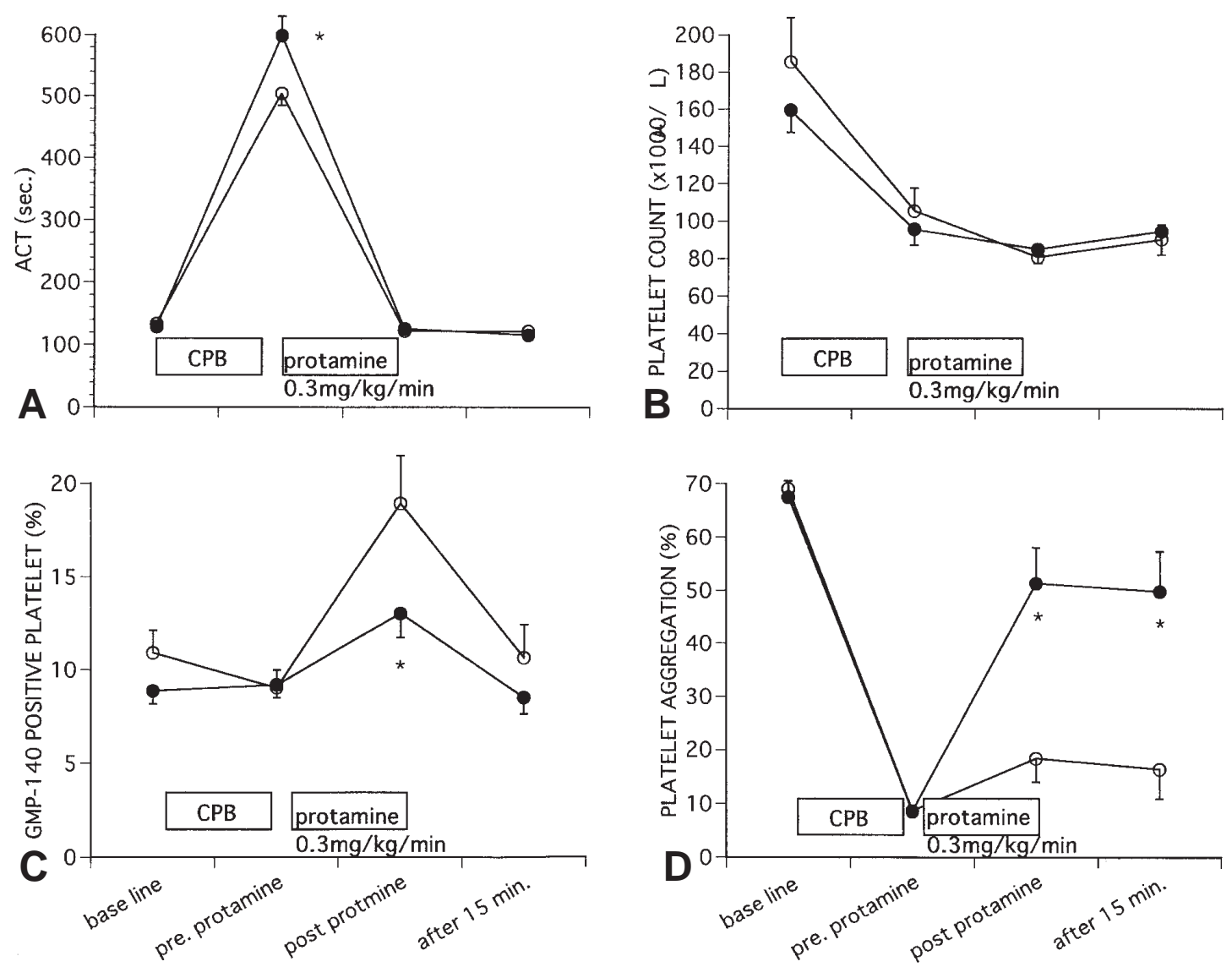

Fig 1. Time course of hematologic values (mean $\pm \mathrm{SE}$ ). $C P B$, Cardiopulmonary bypass; $P$, protamine infusion at a rate of $0.3 \mathrm{mg} \cdot \mathrm{kg}^{-1} \cdot \mathrm{min}^{-1}$. The duration of protamine infusion was 10 minutes in control group and about 5 minutes in titration group. $\bigcirc-\bigcirc$, Control group $(n=14)$; $-\odot$, titration group $(n=20)$. ${ }^{*} P<.05$ between control and titration groups by the Student unpaired $t$ test at given times. A, Whole blood activated clotting time; B, platelet count; C, CD62-FITC (monoclonal antibodies to GMP-140) positive platelets (percent); and D, washed platelet aggregation to thrombin. The concentrations of thrombin were $0.12 \pm 0.06 \mathrm{unit} / \mathrm{mL}$ in the control group and $0.10 \pm 0.03 \mathrm{unit} / \mathrm{mL}$ in the titration group.

cells. Platelet $\alpha$-granule secretion was monitored by detecting GMP-140 (CD62) expression on platelet surface. The threshold level for GMP-140-negative cells was set so as to include $99 \%$ of nonstained platelets.

Because of sedimentary formation, the washed platelets that were incubated with protamine (in vitro study) were stained directly without fixation by paraformaldehyde.

Platelet aggregation. Platelet aggregation was studied with a Hema Tracer device (SSR Engineering Co Ltd, Tokyo, Japan). The threshold concentration of thrombin (ie, the lowest concentration of the agonist capable of producing irreversible aggregation of at least $60 \%$ to $70 \%$ light transmission of buffer in 5 minutes) was determined with the sample obtained before the operation. The same concentration of thrombin was used to determine the percent aggregation of washed platelets in all subsequent samples.

$\beta$-Thromboglobulin concentration. In the in vitro study, $400 \mu \mathrm{L}$ of washed platelets $\left(1.0 \times 10^{9} / \mathrm{mL}\right)$ was incubated with protamine (up to $100 \mu \mathrm{g} / \mathrm{mL}$ ) for 5 minutes at room temperature. After being mixed with $100 \mu \mathrm{L}$ of ACD solution, the sample was centrifuged at $400 \mathrm{~g}$ for 15 minutes and the supernatant was stored at $-20^{\circ} \mathrm{C}$. The concentration of $\beta$-thromboglobulin in the supernatant was measured with the enzymelinked immunosorbent assay kits (Diagnostica, Stago, France).

Statistical analysis. The results in Table I were expressed as the mean \pm standard deviation. The effects of protamine on GMP-140 expression and platelet aggregation at various times during the operation were expressed as the mean \pm standard error and compared by the Student unpaired $t$ test and analysis of variance with Bonferroni correction.

\section{Results}

Phase I (ex vivo, patient analysis). No differences between the groups were identified with regard to demo- 

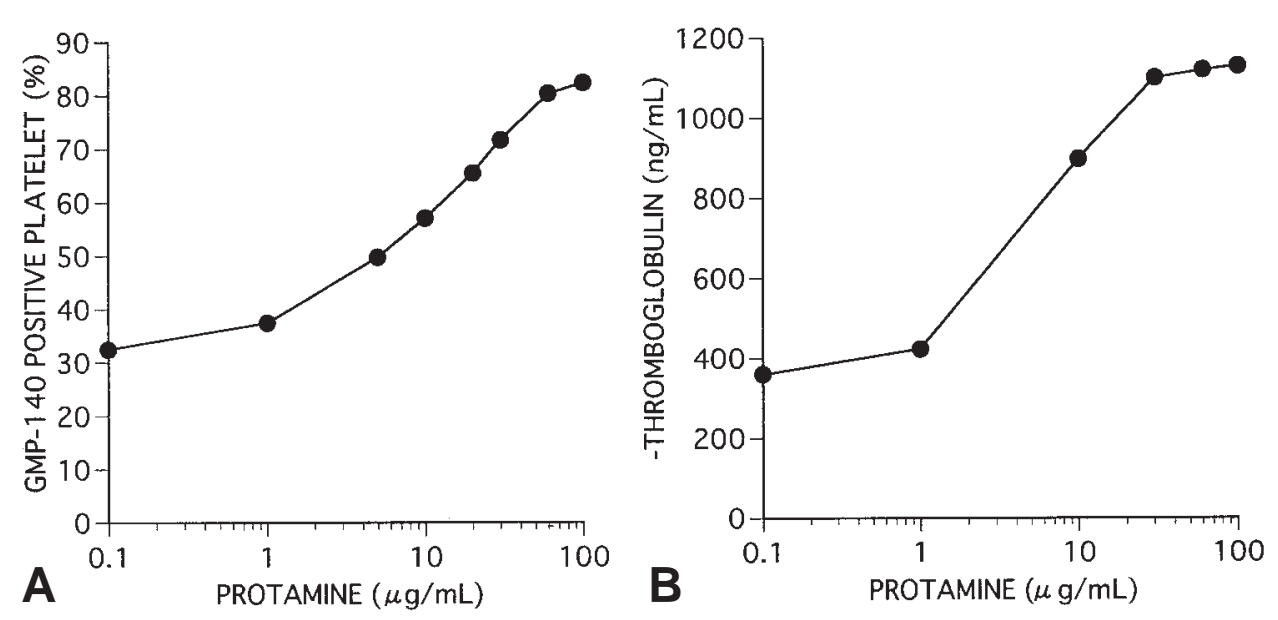

Fig 2. Effect of protamine on platelet $\alpha$-granule secretion (A) and $\beta$-thromboglobulin (B). Washed platelets were incubated with protamine for 5 minutes at room temperature and fixed with $1 \%$ paraformaldehyde followed by flow cytometric or enzyme-linked immunosorbent assay analysis.

graphic data and duration of CPB (Table I). Titration group patients received greater doses of heparin than control group patients and had significantly higher concentrations of heparin after CPB. By contrast, mean protamine dose administered in the titration group was significantly lower than that in the control group.

Additional heparin was administered when ACTs were less than 480 seconds and, as a result, each ACT during CPB was kept at more than 400 seconds in both groups (Fig 1, A). Although the protamine doses administered in titration group patients were about half the doses of the control group, the ACTs in the titration group returned to $108 \%$ of the baseline values at the end of protamine infusion. In addition, the ACTs in the titration group (115 \pm 11 seconds) were less than those in the control group $(121 \pm 20$ seconds) 15 minutes after protamine administration. No heparin rebound was observed, and additional protamine doses were not required in either group.

Compared with samples obtained before protamine administration, whole blood platelet counts in the titration group showed only an $8 \%$ decrease at the end of protamine administration, whereas platelet counts in the control group decreased 13\% temporarily (Fig 1, $B$ ). The percentages of GMP-140-positive platelets significantly increased in control group patients but remained lower in titration group patients at the end of protamine administration (Fig 1,C).

The threshold concentrations of thrombin that caused $60 \%$ to $70 \%$ aggregation in the samples obtained before the operation were $0.12 \pm 0.06 \mathrm{unit} / \mathrm{mL}$ in control group patients and $0.10 \pm 0.03 \mathrm{unit} / \mathrm{mL}$ in titration

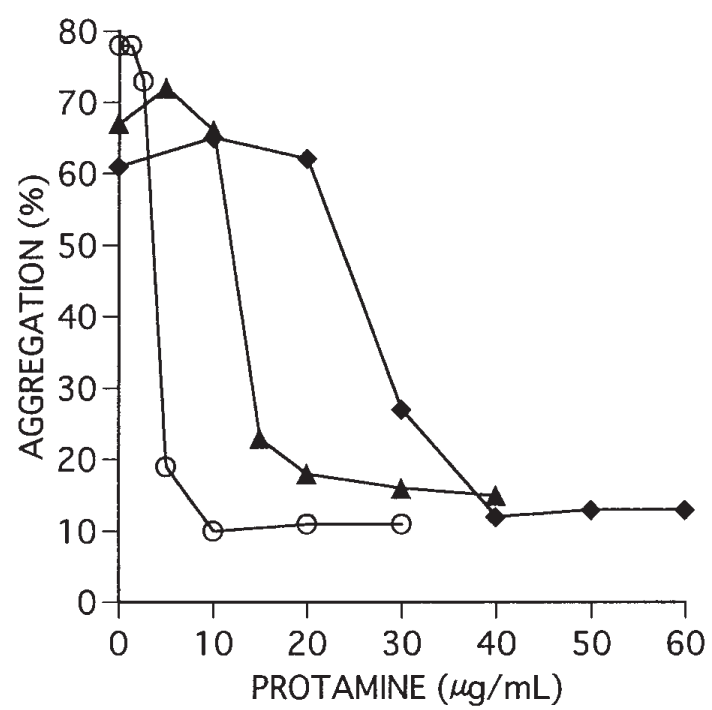

Fig 3. Washed platelets were incubated with buffer $(\bigcirc-\bigcirc), 1$ unit/mL $(\boldsymbol{\Delta}-\boldsymbol{\Lambda})$ or 3 units/mL $(\bullet-\bullet)$ of heparin for 5 minutes followed by incubation with protamine (up to $60 \mu \mathrm{g} / \mathrm{mL}$ ) for 5 minutes at room temperature. Then, platelet aggregation induced by thrombin $(0.1 \mathrm{unit} / \mathrm{mL})$ was measured by a Hema Tracer device.

group patients. The aggregation of washed platelets to thrombin was suppressed during CPB in both groups; however, $80 \%$ recovery of aggregation compared with baseline values was observed after protamine infusion in the titration group (Fig 1,D). In contrast, the percentage remained lower $(<26 \%)$ after protamine administration in control group patients. 
Phase II (in vitro, volunteer analysis). Protamine, incubated with washed platelets for 5 minutes at room temperature, increased the percentage of GMP-140positive platelets (Fig 2,A) and $\beta$-thromboglobulin release (Fig 2, $B$ ) in a concentration-related manner. These results indicate that a protamine threshold between 1 and $10 \mu \mathrm{g} / \mathrm{mL}$ caused the $\alpha$-granule secretion of washed platelets.

To evaluate the influence of heparin and protamine on platelet aggregation, we incubated washed platelets with buffer or heparin (1-3 units $/ \mathrm{mL}$ ) for 5 minutes at room temperature followed by incubation with protamine (up to $60 \mu \mathrm{g} / \mathrm{mL}$ ) for 5 minutes at $37^{\circ} \mathrm{C}$. Then platelet aggregation stimulated by $0.1 \mathrm{unit} / \mathrm{mL}$ of thrombin was measured (Fig 3). In the sample without heparin, low-dose protamine $(>5 \mu \mathrm{g} / \mathrm{mL})$ reduced the aggregation of washed platelets stimulated by thrombin. Heparin itself slightly attenuated the platelet aggregation to thrombin, which suspended in the buffer without antithrombin III. Lower concentration of protamine relative to heparin concentration restored the platelet aggregation to thrombin that was impaired by heparin. However, excess concentration of protamine compared with heparin lessened the aggregation of washed platelets to thrombin. Protamine $(10 \mu \mathrm{g} / \mathrm{mL})$ related platelet inhibition was overcome by greater doses ( $>0.3$ unit $/ \mathrm{mL}$ ) of thrombin, but there was a time lag (about 5 minutes) to the start of aggregation after thrombin injection.

\section{Discussion}

Protamine itself, not heparin or the protamine-heparin complex, is responsible for its multifactorial toxicity. ${ }^{5}$ Protamine has been found to be toxic to endothelial cells and cardiac myocytes, and it has been shown to enter the interstitium of organs such as the heart, directly affecting cellular function. ${ }^{6}$ Mechanisms suggested to explain toxicity have included direct vasodilation and depression of cardiac function, ${ }^{7}$ release of histamine, ${ }^{3}$ immunologic abnormalities, ${ }^{8}$ generation of thromboxane, ${ }^{9}$ inhibition of carboxypeptidase $\mathrm{N}$ in the plasma, ${ }^{2}$ and activation of complement. ${ }^{10}$ Total cationic charge appears to be an important determinant for both anticoagulation reversal and toxicity of protamine-like peptides. ${ }^{11}$

The effects of protamine on platelets also have been well documented. Jaques ${ }^{12}$ in 1949 reported significant thrombocytopenia associated with protamine administration. Machi, Sigel, and Feinberg ${ }^{13}$ showed that platelet aggregation was induced by protamine before clots formed and that not only shear rate but also platelet activation might affect the rate and composition of plasma clots. Wakefield, Whitehouse, and
Stanley ${ }^{14}$ reported that platelet count decreased by up to $74 \%$ after reversal of heparinization with protamine in dogs. In this study, platelet counts of control group patients did not decrease significantly after protamine administration. The reason may be that the protamine doses were not based on the total heparin doses but rather on the initial heparin doses. Lindblad and colleagues ${ }^{15}$ studied the effect of protamine sulfate on platelet function and found that protamine inhibits thrombin-induced platelet aggregation. Ammar and Fisher ${ }^{4}$ reported that platelet reactivity to thrombin receptor agonist peptide was markedly inhibited by protamine. Both heparin and protamine attenuate platelet aggregation to thrombin, but the mechanisms are quite different. Our in vitro study showed that protamine threshold between 1 and $10 \mu \mathrm{g} / \mathrm{mL}$ released $\alpha$ granules of washed platelets; in other words, protamine activated platelets. Although increased thrombin concentration $(>0.3$ unit $/ \mathrm{mL})$ may aggregate washed platelets after incubation with protamine, it is unclear whether these concentrations are achieved either locally or systemically in vivo. ${ }^{16}$ In contrast, heparin did not release $\alpha$-granules of washed platelets (data not shown), and the attenuated platelet aggregation to thrombin was restored by an adequate amount of protamine. These findings indicated that there may be two separate mechanisms for preservation of platelet function during $\mathrm{CPB}$ : higher heparin concentration and lower protamine concentration.

To prevent protamine toxicity, attempts have been undertaken to produce positively charged designer peptides that would safely reverse standard unfractionated heparin. ${ }^{11}$ Other approaches for reversal of heparin anticoagulation unrelated to protamine exist, such as platelet factor $4,{ }^{17,18}$ heparinase, ${ }^{4}$ and filter systems, ${ }^{19}$ but they too have limitations. ${ }^{20}$ Because protamine sulfate is the only current agent approved by the Food and Drug Administration for intraoperative reversal of heparin anticoagulation, ${ }^{20}$ appropriate administration of protamine after CPB is important to reduce its side effects. For example, slow protamine administration decreased the magnitude of the adverse responses, ${ }^{21}$ and reduced protamine doses were associated with significant decreases in blood product use and postoperative bleeding. ${ }^{22,23}$ Despotis and associates ${ }^{24}$ indicated that greater doses of heparin and lower doses of protamine relative to heparin dose, based on the point-ofcare monitoring of heparin concentration by an automated protamine sulfate titration method, were associated with reduced blood use. They suggest that this effect is due partly to better preservation of the coagulation system, including platelet function. 
At present, when protamine is used to reverse standard-unfractionated heparin anticoagulation, two practical approaches may be used: a fixed dose of protamine (such as 1.2 to $1.5 \mathrm{mg} / 100 \mathrm{IU}$ of previously administered heparin) or a technique called protamine titration, in which the amount of protamine administered is directly matched to the amount of heparin circulating at the time of reversal. ${ }^{20}$ Advantages of the second approach with protamine titration include a lessening of the amount of protamine with a potential decrease in toxicity, and disadvantages include the potential for bleeding from heparin rebound and the subsequent need to administer more protamine. ${ }^{20}$ In this study, protamine doses in the titration group were less than half the doses in the control group and one third of the values that were based on whole heparin doses. Nevertheless, the ACTs in titration group patients returned to almost normal range, and no signs of heparin rebound were observed. The data on heparin concentration by the Hepcon system showed that heparin concentration decreased during CPB, even though ACTs were kept higher than 400 seconds. The reason is that the ACTs are prolonged not only by heparin but also by hemodilution or hypothermia. As a result, protamine doses based on the initial heparin doses exceed the residual heparin doses in control group patients. GMP-140-positive platelet studies and platelet aggregation to thrombin in the control group indicate that excess protamine, compared with heparin concentration before protamine administration, activated platelets and attenuated platelet aggregation to thrombin. In the titration group, lower doses of protamine than the heparin dose restored platelet reactivity to thrombin that was depressed during CPB. These data imply that appropriate protamine administration for reversal of heparin anticoagulation preserves platelet function and may reduce blood product use.

\section{Conclusions}

Administration of the minimum required dose of protamine based on the protamine-heparin titration data reduces platelet activation and preserves platelet responses to thrombin after CPB. Protamine might be used more safely and effectively by the automated heparin-protamine titration method.

\section{REFERENCES}

1. Stanley TE III, Reves JG. Cardiovascular monitoring. In: Millear RD, editor. Anesthesia, 4th ed. New York: Churchill Livingstone; 1994. p. 1161-228.

2. Tan F, Jackman H, Skidgel RA, Zsigmond EK, Erdos EG. Protamine inhibits plasma carboxypeptidase N, the inacti- vator of anaphylatoxins and kinins. Anesthesiology 1989; 70:267-75.

3. Horrow JC. Protamine: a review of its toxicity. Anesth Analg 1985;64:348-61.

4. Ammar T, Fisher CF. The effects of heparinase 1 and protamine on platelet reactivity. Anesthesiology 1997;86:1382-6.

5. Hird RB, Crawford FA Jr, Mukherjee R, Zile MR, Spinale FG. Effects of protamine on myocyte contractile function and beta-adrenergic responsiveness. Ann Thorac Surg 1994;57: 1066-74.

6. Hird RB, Wakefield TW, Mukherjee R, Jones BU, Crawford FA, Andrews PC, et al. Direct effects of protamine sulfate on myocyte contractile processes: cellular and molecular mechanisms. Circulation 1995;92(Suppl):II433-46.

7. Goldman BS, Joison J, Austen WG. Cardiovascular effects of protamine sulfate. Ann Thorac Surg 1969;7:459-71.

8. Weiss ME, Nyhan D, Peng ZK, Horrow JC, Lowenstein E, Hirshman C, et al. Association of protamine IgE and IgG antibodies with life-threatening reactions to intravenous protamine. N Engl J Med 1989;320:886-92.

9. Morel DR, Lowenstein E, Nguyenduy T, Robinson DR, Repine JE, Chenoweth DE, et al. Acute pulmonary vasoconstriction and thromboxane release during protamine reversal of heparin anticoagulation in awake sheep: evidence for the role of reactive oxygen metabolites following nonimmunological complement activation. Circ Res 1988;62:905-15.

10. Weiler JM, Gellhaus MA, Carter JG, Meng RL, Benson PM, Hottel RA, et al. A prospective study of the risk of an immediate adverse reaction to protamine sulfate during cardiopulmonary bypass surgery. J Allergy Clin Immunol 1990;85:713-9.

11. DeLucia A III, Wakefield TW, Andrews PC, Nichol BJ, Kadell AM, Wrobleski SK, et al. Efficacy and toxicity of differently charged polycationic protamine-like peptides for heparin anticoagulation reversal. J Vasc Surg 1993;18:49-58.

12. Jacques LB. A study of the toxicity of the protamine salmine. $\mathrm{Br}$ J Pharmacol 1949;4:135-44.

13. Machi J, Sigel B, Feinberg H. Protamine-induced platelet aggregation and clotting investigated by ultrasound. Haemostasis 1987; 17:226-34.

14. Wakefield TW, Whitehouse WM Jr, Stanley JC. Depressed cardiovascular function and altered platelet kinetics following protamine sulfate reversal of heparin activity. J Vasc Surg 1984;1:34655.

15. Lindblad B, Wakefield TW, Whitehouse WM Jr, Stanley JC. The effect of protamine sulfate on platelet function. Scand J Thorac Cardiovasc Surg 1988;22:55-9.

16. Shuman MA, Majerus PW, The measurement of thrombin in clotting blood by radioimmunoassay. J Clin Invest 1976;58: 1249-58.

17. Korutla LN, Stewart GJ, Lasz EC, Maione TE, Niewiarowski S. Evaluation of recombinant platelet factor 4 and protamine sulfate for heparin neutralization: clotting and clearance studies in rat. Thromb Haemost 1994;71:609-14.

18. D'Ambra M. Restoration of the normal coagulation process: advances in therapies to antagonize heparin. J Cardiovasc Pharmacol 1996;27(Suppl 1):S58-62.

19. Yang VC, Port FK, Kim JS, Teng CL, Till GO, Wakefield TW. The use of immobilized protamine in removing heparin and preventing protamine-induced complications during extracorporeal blood circulation. Anesthesiology 1991;75:288-97. 
20. Wakefield TW, Stanley JC. Intraoperative heparin anticoagulation and its reversal. Semin Vasc Surg 1996;9:296-302.

21. Wakefield TW, Hantler CB, Wrobleski SK, Crider BA, Stanley JC. Effects of differing rates of protamine reversal of heparin anticoagulation. Surgery 1996;119:123-8.

22. DeLaria GA, Tyner JJ, Hayes CL, Armstrong BW. Heparin-protamine mismatch: a controllable factor in bleeding after open heart surgery. Arch Surg 1994;129:944-50.

23. Jobes DR, Aitken GL, Shaffer GW. Increased accuracy and pre- cision of heparin and protamine dosing reduces blood loss and transfusion in patients undergoing primary cardiac operations. J Thorac Cardiovasc Surg 1995;110:36-45.

24. Despotis GJ, Joist JH, Hogue CW Jr, Alsoufiev A, Kater K, Goodnough LT, et al. The impact of heparin concentration and activated clotting time monitoring on blood conservation: a prospective, randomized evaluation in patients undergoing cardiac operation. J Thorac Cardiovasc Surg 1995; 110:46-54.

\section{ON THE MOVE?}

Send us your new address at least six weeks ahead

Don't miss a single issue of the journal! To ensure prompt service when you change your address, please photocopy and complete the form below.

Please send your change of address notification at least six weeks before your move to ensure continued service. We regret we cannot guarantee replacement of issues missed due to late notification.

\section{JOURNAL TITLE:}

Fill in the title of the journal here.

\section{OLD ADDRESS:}

Affix the address label from a recent issue of the journal here.

\section{NEW ADDRESS: \\ Clearly print your new address here.}

Name

Address

City/State/ZIP

\section{COPY AND MAIL THIS FORM TO:}

Periodical Subscription Services

Mosby, Inc.

11830 Westline Industrial Dr.

St. Louis, MO 63146-3318
OR FAX TO:

314-432-1158

N/ Mosby

\section{OR PHONE:}

1-800-453-4351

Outside the U.S., call

314-453-4351 